\title{
Seismic Evaluation of Masonry Buildings Strengthened with Reinforced Concrete Beams and Columns
}

\author{
An Dong ${ }^{*}$, Qu Tiejun \\ School of Civil Engineering, North China University of Technology, Beijing \\ *hadesloveln@163.com
}

\begin{abstract}
Keywords: Seismic Behavior, Pseudo-dynamic Test, Lateral Cyclic Load, Stiffness Degradation Abstract. The pseudo-dynamic seismic tests and lateral cyclic load tests for tie-columns and ringbeams confined masonry structure according to the seismic requirements and masonry structure strengthened with reinforced concrete beams and columns have been carried out. Cracks propagation pattern, hysteretic curves, skeleton curves and stiffness degradation curves were compared and analyzed. The results from tests show that the brick masonry building with tiecolumns and ring-beams has good ductility. The brick masonry building strengthened by RC beamcolumn can keep bearing capacity after serious cracking of masonry wall. The brick building strengthened by RC beam-column can satisfy the requirements of the seismic fortification criterion. The RC beam and column can be used as reinforcement measure to improve the seismic performance of brick buildings.
\end{abstract}

\section{Introduction}

Brick masonry structure is widely common in China. This type of structure is simple and easy constructed, applied in most of rural residential and public buildings. In previous earthquakes, a large number of masonry structures suffered various damage. In Wenchuan earthquake (2008.5.12), most of collapsed brick buildings without tie-columns or ring-beams had weaker seismic system, and the precast slabs had no tied [1]. In Lushan earthquake (2013.4.20), the seismic damage patterns of masonry residential building without standard seismic design are complicated [2]. The masonry buildings are used in urban construction, and seismic design is an important item on the development of masonry structure. Confined masonry with tie-columns and ring-beams apply in post-earthquake reconstruction. Reinforcement has been added to improve the resistance of masonry. To improve the seismic performance of masonry structure is still concerned in recent research.

Two masonry buildings are designed and fabricated in this paper. One is brick masonry building with tie-columns and ring-beams, simultaneously; the other is strengthened with concrete columns and beams. Pseudo-dynamic and lateral cyclic load tests on two models were carried out in order to contrast failure mechanism and seismic performance of buildings, as well as evaluate the effect of strengthening with concrete columns and beams.

\section{Building Design and Fabrication}

The single-bay, single-depth and two-floor building with precast concrete slab was designed and constructed in this test [3-5]. This building is full-scale structure. It was intended to represent some structural characteristics of a typical existing building in China. The dimensions of the building were $3600 \mathrm{~mm}$ by $2400 \mathrm{~mm}$ in plan with story height of $2200 \mathrm{~mm}$. Fired common clay bricks with $240 \mathrm{~mm} \times 115 \mathrm{~mm} \times 53 \mathrm{~mm}$ were applied in the buildings. The wall was designed with $240 \mathrm{~mm}$ in thickness. The masonry structure was constructed on the concrete foundation slab.

$\mathrm{CM}$ is brick masonry building with tie-columns and ring-beams according to code or design of masonry structures [4]. The size of the cross-section of the structural column which set at four comers of the buildings is $240 \mathrm{~mm} \times 240 \mathrm{~mm}$. The vertical steel reinforcements inside the column is $4 \Phi 12$, while the hooping thereof, $\phi 6$ is adopted for common position with a spacing of $200 \mathrm{~mm}$. Concrete ring beams are placed at the floor. The size of the section of the ring beam is $150 \mathrm{~mm} \times 240 \mathrm{~mm}$, while its longitudinal steel reinforcements is $4 \Phi 12$. $\Phi 6$ is used with a spacing of 
$200 \mathrm{~mm}$ for hooping of beam. The intersection between the brick masonry and the structural column is laid into a shape of horse tooth joint with restrained steel reinforcements placed every $500 \mathrm{~mm}$ along the wall height. RM is brick masonry building strengthened with concrete columns and beams. According to the code for strengthening 10, the size of the cross-section of the structural column which set at exterior comers of the buildings is $600 \mathrm{~mm} \times 600 \mathrm{~mm}$. The vertical steel reinforcements inside the column is $12 \Phi 12$, while the hooping thereof, $\phi 6$ is adopted for common position with a spacing of $200 \mathrm{~mm}$. Concrete ring beams are the same as CM. The rod of $2 \Phi 12$ placed every $500 \mathrm{~mm}$ along the wall height between the masonry wall and the exterior concrete column, anchoring through the concrete pins. The concrete strength grade of columns and beams is C25. The floor and roof adopt two precast reinforced concrete slabs. Door and window frames were constructed of timber sections. Views of the test buildings CM and RM are shown in Fig.1.

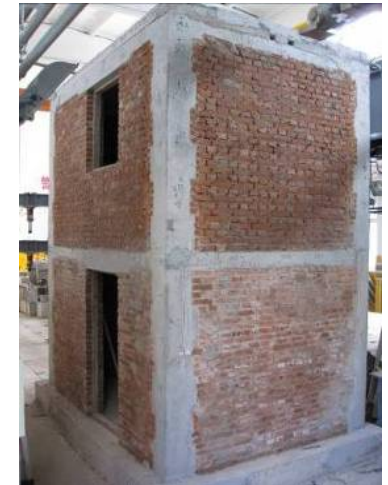

(a) $\mathbf{C M}$

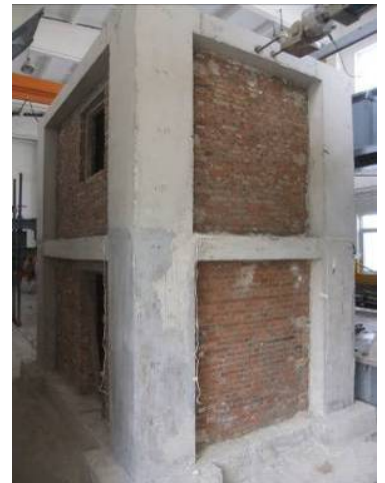

(b) $\mathbf{R M}$

Fig.1 Experimental models

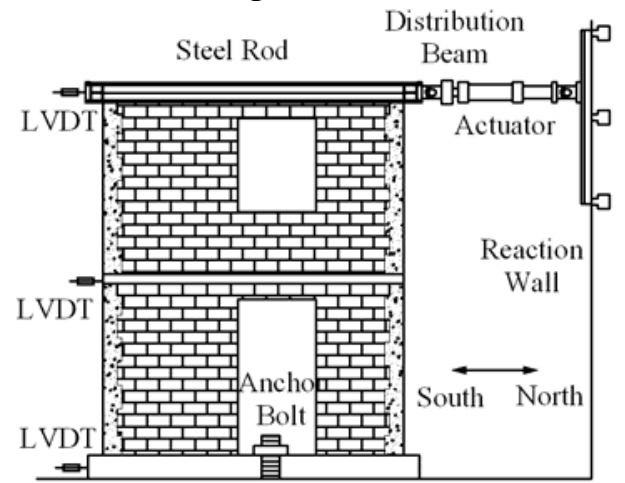

Fig.2 Test loading system

\section{Test System}

The test setup consisted of one $500 \mathrm{kN}$ and $\pm 250 \mathrm{~mm}$ actuators located at the roof level, as shown in Fig.2. The steel-rod-beam was used to connect the actuators to the masonry walls at the connection points. The test was conducted in displacement control, with a displacement profile based on the first vibration mode. The structure was loaded with increasing roof displacements and included one complete displacement cycles at each drift level. The displacements of the building under loading were measured by means of a set of LVDTs.

\section{Ground Acceleration Selection}

N-S component of San Gabriel of Northridge earthquake $(\mathrm{Ms}=6.7)$ of April 17. 1994, has been used to simulate the earthquake ground motion. The duration of the record is $46 \mathrm{~s}$ (strong phase is $15 \mathrm{~s}$ long), with peak ground acceleration 135gal. According to code [3], the acceleration record has been scaled to $180 \%$ assuming that models will be tested (Fig.3). The peak ground acceleration of model earthquake is 220 gal. Consequently, the duration has been reduced to $30 \mathrm{~s}$, whereas the accelerations remained unchanged. As can be seen in Fig.4, the response spectrum of the model earthquake for $5 \%$ of critical damping is contrast with the elastic spectrum [3].

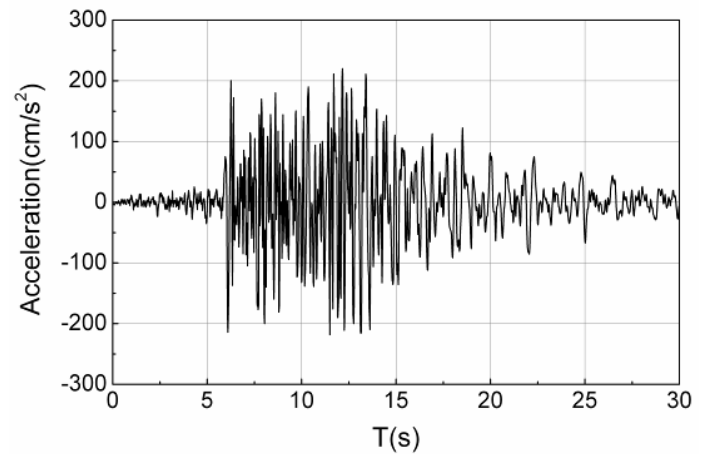

Fig. 3 Acceleration time-history of earthquake

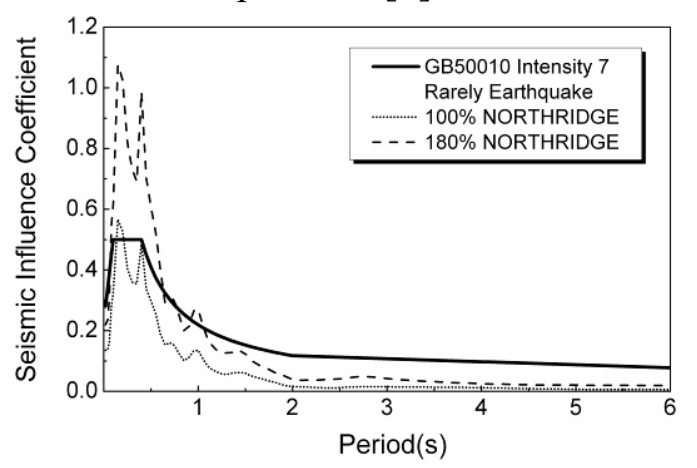

Fig. 4 Spectrum of scaled ground motions 


\section{Earthquake Response}

The maximum value of seismic response can be seen in Table 2.The peak displacement of CM and $\mathrm{RM}$ is $1.48 \mathrm{~mm}$ and $1.42 \mathrm{~mm}$ respectively. The maximum resistance of $\mathrm{CM}$ and $\mathrm{RM}$ is $81.5 \mathrm{kN}$ and $104.7 \mathrm{kN}$. The peak acceleration of CM and RM is $546.7 \mathrm{~cm} / \mathrm{s} 2$ and $553.5 \mathrm{~cm} / \mathrm{s} 2$ 。 The acceleration amplification coefficient of the two models is respectively 2.49 and 2.52 .

Table 2 Seismic response of building during pseudo-dynamic tests

\begin{tabular}{|c|c|c|c|}
\hline & Acceleration[cm/s2] & Displacement [mm] & Force[kN] \\
\hline \multirow{2}{*}{$\mathrm{CM}$} & 546.7 & 1.48 & 81.5 \\
\cline { 2 - 4 } & -526.9 & -1.11 & -85.0 \\
\hline \multirow{2}{*}{$\mathrm{RM}$} & 553.5 & 1.42 & 104.7 \\
\cline { 2 - 4 } & -553.9 & -1.18 & -103.3 \\
\hline
\end{tabular}

\section{Force-Displacement Hysteretic Behavior}

Complete hysteresis loops between lateral resistant force versus roof displacement are shown in Fig.10. In the curves shown in Fig.8, maximum displacement values ( $\Delta \mathrm{PsD})$ and envelopes are also presented. In the lateral cyclic load test, maximum displacement values of $\mathrm{CM}$ and $\mathrm{RM}$ are $63.95 \mathrm{~mm}$ and $47.88 \mathrm{~mm}$, as shown in Fig.5. Hysteretic curve cycles mostly linearly at the first stage of the test. It is evident from the figure that with displacement increases, stiffness (slope of the curve) decreases, and the area under the hysteresis loops increases. The shape of hysteresis loops transfer from spindle -shape to the anti- S. After masonry wall cracking, lateral stiffness of CM decreases rapidly. The ultimate lateral load of model RM is greater than model CM.

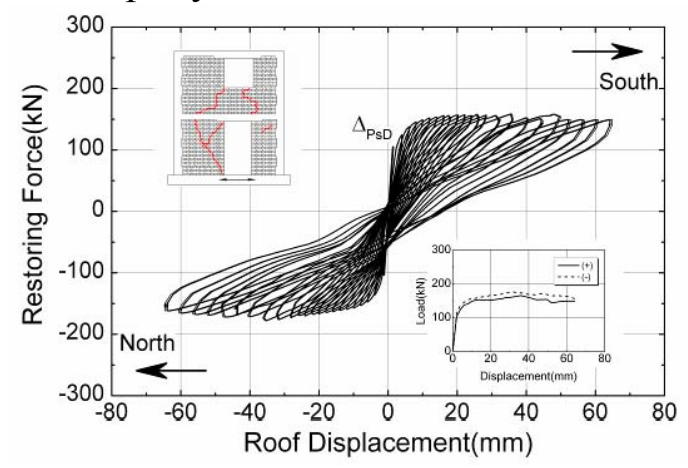

(a)

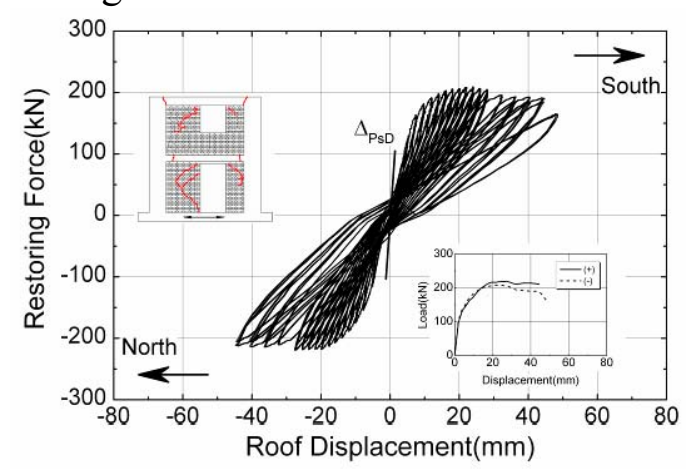

(b)

Fig.5 Hysteretic curves during low cyclic tests: (a) CM; (b) RM

\section{Conclusions}

Two masonry buildings have been tested by subjecting them to pseudo-dynamic and lateral cyclic load tests. Seismic performance of buildings, as well as the effect of strengthening with concrete columns and beams has been contrasted and evaluated.

The confined system of tie-column and ring-beam is effective to improve the poor seismic performance of the common brick masonry, by enhancing the lateral load bearing capacity. Reinforced concrete column and beam play an important role for improving the structural integrity.

The masonry building strengthened by reinforced concrete beams and columns can satisfy the seismic fortification criterion at present in the seismic intensity 7 or more zone in China.

\section{Conflict of Interests}

The authors declare that there is no conflict of interests regarding the publication of this paper. 


\section{Acknowledgments}

This paper was financially supported by Beijing Natural Science Foundation (8142015) and "Undergraduate training-Approval and research of teaching reform-Experimental spot of educational reform of continuing education in colleges"(Project encoding in the college:150078).The authors' deeply express sincere appreciation to them.

\section{References}

[1].Civil and Structural Groups of Tsinghua University, Xinan JiaotongUniversity and Beijing Jiaotong University, Journal of Building Structures, Vol.29,No.4,Aug. (2008)

[2]. Tao Wang, Yongquan Zhang, etc, Journal of Earthquake Engineering and Engineering Vibration", Vol.33, No.3, Jun. (2013)

[3]. Code for Seismic Design of Buildings, (GB50011-2010), China Architecture \& Building Press, Beijing, (2010)

[4]. Code for Design of Masonry Structures, (GB50003-2011), China Architecture \& Building Press, Beijing, (2011)

[5]. Technical Specification for Seismic Strengthening of Buildings, (JGJ116-2009), China Architecture \& Building Press, Beijing, (2009)

[6]. M. Tomaževič, I. Klemenc, Earthquake Engineering \& Structural Dynamics, Vol.26, (1997)

[7]. Specification of testing methods for earthquake resistance building, (JGJ101-96), China Architecture \& Building Press, Beijing, (1997) 